\title{
Comparison of the Water Quality between the Surface Microlayer and Subsurface Water in Typical Water Bodies in Sichuan
}

\author{
Jiang Yu ${ }^{1}$, Yonghong Shui ${ }^{2}$, Waitim $\mathrm{Ho}^{3}$, Jianquan Liu ${ }^{4}$, Xin $\mathrm{Yi}^{1}$, Hao Wang ${ }^{1}$, \\ Fang Zhang ${ }^{1}$ \\ ${ }^{1}$ College of Architecture and Environment, Sichuan University, Chengdu, China \\ ${ }^{2}$ Department of Dyeing Chemistry \& Environmental Engineering, Chengdu Textile College, Chengdu, China \\ ${ }^{3}$ Commission on Environmental Consultation, Macao SAR Government, Macao, China \\ ${ }^{4}$ Chengdu Electromechanical College, Chengdu, China \\ E-mail:Yujianggz@163.com \\ Received August 7, 2010; revised August 24, 2010; accepted August 31, 2010
}

\begin{abstract}
Investigation and assessment of water quality status in the surface microlayer (SML) and subsurface water (SSW) in several kinds of typical water bodies in Sichuan were carried out from May to June 2010. The results showed that N, P were enriched to some extent at SML in Xichi pool, Funan River and Longquan reservoir, which made concentrations of the indexes such as total nitrogen (TN), total phosphorus (TP), chemical oxygen demand (COD) of SML be much higher than those of SSW $(\mathrm{P}<0.05)$, and the exceeding rates were up to $100 \%$. The contents of TN, TP, COD of SML and SSW in Xichi pool, and Funan River exceeded III even IV level of water quality standard, while these indexes in Longquan reservoir were lower than III or II level of water quality standard. Though Chl. $a$ mass concentration at SML and SSW in Funan River was prominently lower than those in Xichi pool and Longquan reservoir, according to the eutrophic evaluation standard, the water bodies of SML and SSW in Funan River and Xichi pool were in middle eutrophication, the highest index of eutrophication (E value) was up to 66.78, while there was light entuophic in Longquan reservoir, and there had obvious difference with $\mathrm{E}$ value and $\mathrm{COD}, \mathrm{TP}, \mathrm{TN}(\mathrm{P}<0.05)$. This research shows that the water quality of Longquan reservoir is generally well. While Funan River is a middle eutrophication, and its pollution is more serious than Xichi pool, the two waters belong to national III even IV level, and SML has the capability of enrichment to the pollutants such as N, P.
\end{abstract}

Keywords: Surface Microlayer, Eutrophication, Subsurface Water, Funan River, Assessment

\section{Introduction}

Total water resources in Sichuan Province are rich in years of average rainfall across the province about 488.975 billion cubic meters. However, due to the complex terrain of Sichuan, a large number of domestic sewage, industrial waste and agricultural irrigation water through a variety of different ways into the water body, cause physical and chemical properties of water environment and the spatial distribution of biological communities to change, then to effect the optimization of regional water resources configuration and aquatic ecosystems virtuous circle.

Surface Microlayer (SML) is the interface between air and water. The SML has been generally considered to be enriched, relatively to subsurface water (SSW), with various chemical and microbiological components. Compared to SSW, the SML normally contains relatively high amounts of nutrients, organic carbon, phytoplankton and bacteria [1-3]. Numerous substances, especially those with low water solubility and a high lipid/water partitioning coefficient such as polycyclic aromatic hydrocarbons [4] and polychlorinated biphenyls [5], exhibit a strong interfacial affinity. Therefore, SML biota may be exposed to higher levels of pollutants than organisms residing below the underlying water. Properties of the SML influence the flux of gases across the air-water interface [6,7]. Air-water gas exchange may also be affected by chemical and biological processes of contaminants during transport through the SML. 
At present, most national and abroad researchers focus on the study that the concentration, distribution, transformation and enrichment of the heavy metal, organic compound, and nutrient salt have effects on the biology of SML in sea. It is seldom to report the relevant features of pollution of SML in rivers, lakes and reservoirs. In this article, it is the first time to do an investigation and assessment on the water quality status of SML and SSW in three kinds of typical water bodies in Sichuan Province, in order to explore the physicochemical characteristic changes in fresh water, and provide a strong theory basis for environmental protection of water bodies in Sichuan Province.

\section{Materials and Methods}

\subsection{Sampling Points and Water Sampling}

Three kinds of typical water bodies selected in Sichuan Province included man-made lake (Xichi pool), Longquan reservoir and Funan River in this investigation; each type of water set two representative samples. Sampling time was from May to June 2010. Water samplings were collected from SML and subsurface water at the two points respectively.

SML samples were collected using a glass plate technique of Harvey and Burzell [8]. During sampling, a glass plate $(30 \mathrm{~cm} \times 40 \mathrm{~cm})$ was dipped vertically through the water surface and then drawn up at a constant velocity. The water film adhering to the glass plate was wiped off into a sample bottle with a silicone wipe blade. The thickness of the sample obtained with this device was 50-80 $\mu \mathrm{m}$.

SSW samples were collected with a glass bottle from a depth of $20-50 \mathrm{~cm}$.

\subsection{Determination of Water Physicochemical Index}

Chlorophyll $a$, was determined using a UV/Vis spectrometry of Crank [9]. Nutrient determinations were made according to the standard methods [10]. COD $\left(\mathrm{COD}_{\mathrm{Mn}}\right)$ was determined by improved Permanganate Method. Water body eutrophic situation was evaluated by comprehensive nutrition state index method [11].

The enrichment of SML in three types of water bodies was analyzed according to enrichment factor. Enrichment factor $(\mathrm{EF})$ in the micolayer is defined as follows:

$$
\mathrm{EF}=C_{\mathrm{M}} / C_{\mathrm{s}}
$$

where $C_{\mathrm{M}}$ is the concentration of any substance in the microlayer, and $C_{\mathrm{s}}$ is its concentration in the subsurface water. An EF value $>1.0$ was termed an enrichment, while a value $<1.0$ was designated a depletion.

\subsection{Statistical Analyse}

Statistical analyses were done with the software SPSS at the level of significance at $\mathrm{P}<0.05$. All data were reported as means \pm S.D.

\section{Results}

\subsection{Comparison of Physicochemical Characteristics in Typical Water Bodies}

\subsubsection{COD}

The monitoring results of COD of SML and SSW at different sampling sites in Xichi pool, Funan River and Longquan reservoir were shown in Figure 1. From Figure 1, COD contents of SML at all sampling points were higher than those of SSW. According to Environmental

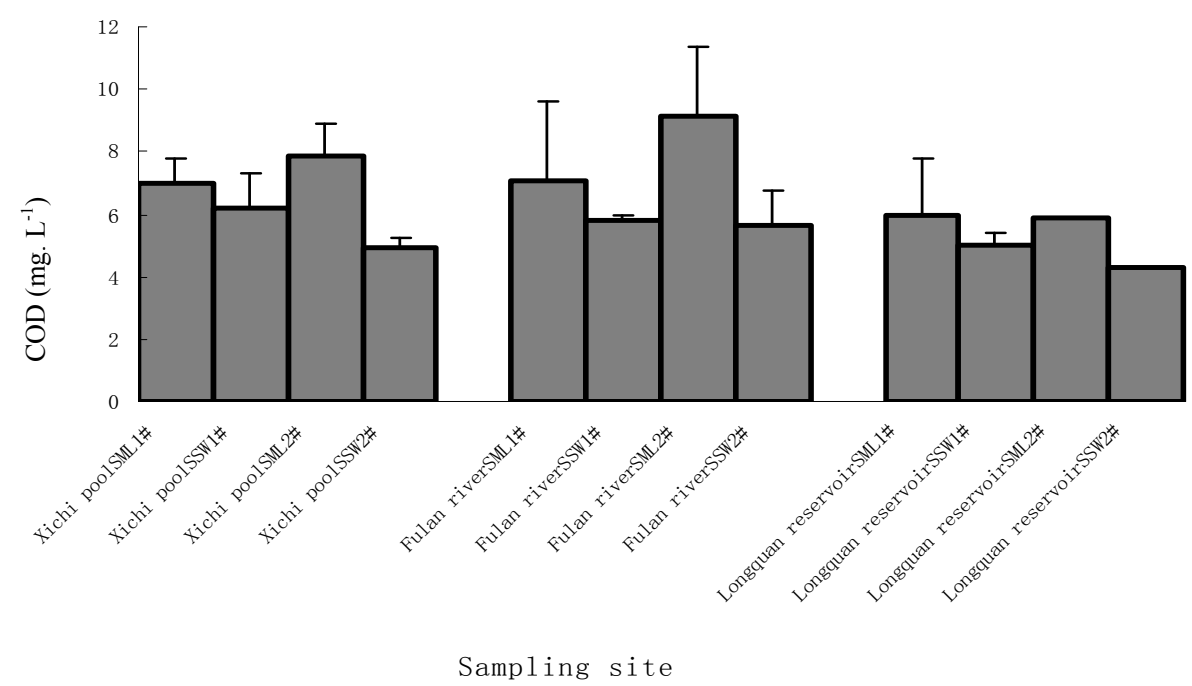

Figure 1. COD contents of SML and SSW at different sampling sites in Xichi pool, Funan River and Longquan reservoir. 
Quality Standard for Surface Water (GB 3838-2002), COD contents of SML in Xichi pool and Funan River exceeded III level of water standard, and the exceeding rates were $100 \%$. COD contents of SML and SSW in Longquan reservoir were lower than III level of water standard, which showed the water quality well in general.

\subsubsection{TP}

TP mass concentrations of SML and SSW at different sampling sites in Xichi pool, Funan River and Longquan reservoir were shown in Figure 2. From Figure 2, there was no obvious difference between TP mass concentrations of SML and that of SSW in Funan River $(\mathrm{P}>0.05)$, but TP mass concentrations of the two layers exceeded III level of water standard with the exceeding rates up to $100 \%$, and higher than those of other two water bodies ( $\mathrm{P}$ $<0.05)$. TP mass concentration ranges of SML and SSW in Longquan reservoir were $0.096 \sim 0.105,0.049 \sim 0.084$ $\mathrm{mg} / \mathrm{L}$, respectively, there was no remarkable difference $(\mathrm{P}>0.05)$.

\subsubsection{TN}

TN mass concentrations of SML and SSW in Xichi pool, Funan River and Longquan reservoir exceeded III, IV and III level of water standard, respectively, and the exceeding rates were up to $100 \%$. Among three kinds of water bodies, the TN mass concentrations of SML were higher than those of SSW, except for $1^{\text {\# }}$ sampling site in Funan River, there was no obvious difference between different layers at other sampling sties (Figure 3).

\subsubsection{Chl. $a$}

Chl. $a$ mass concentrations of SML and SSW in Xichi pool and Longquan reservoir were much higher than those of Funan River (Figure 4). Chl. $a$ mass concentrations of two layers in Funan River were low, and there was no significant difference $(\mathrm{P}>0.05)$. But Chl. $a$ mass concentrations of SSW in Xichi pool exceeded those of SML ( $\mathrm{P}<0.05)$, with an increase by $90.48,55.59 \%$, respectively, compared with the SML; the same monitoring results were shown in Longquan reservoir, but there was no obvious difference between the two layers $(\mathrm{P}>0.05)$.

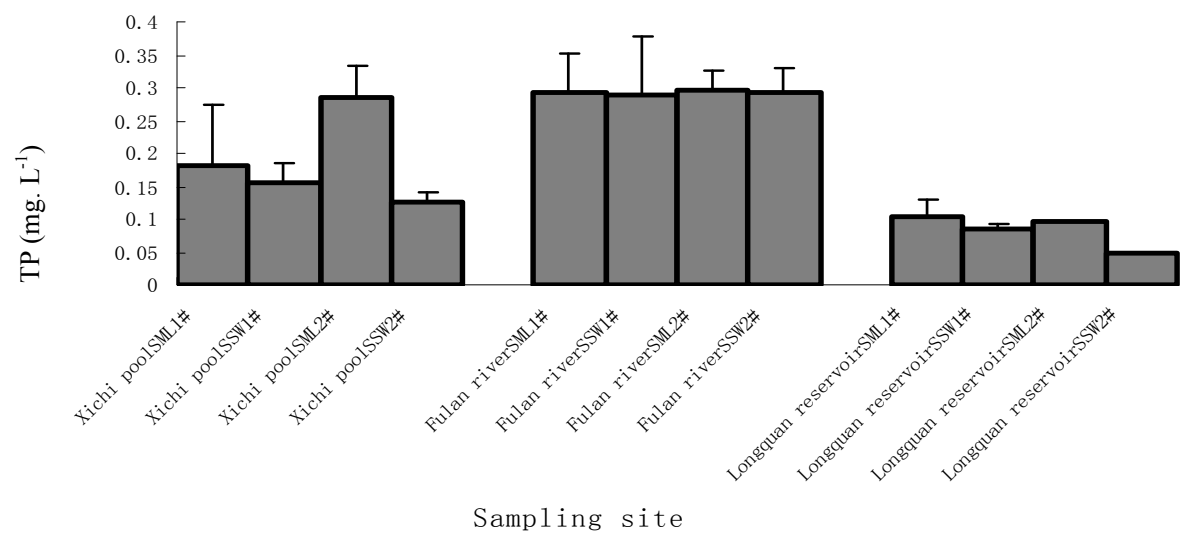

Figure 2. TP contents of SML and SSW at different sampling sites in Xichi pool, Funan River and Longquan reservoir.

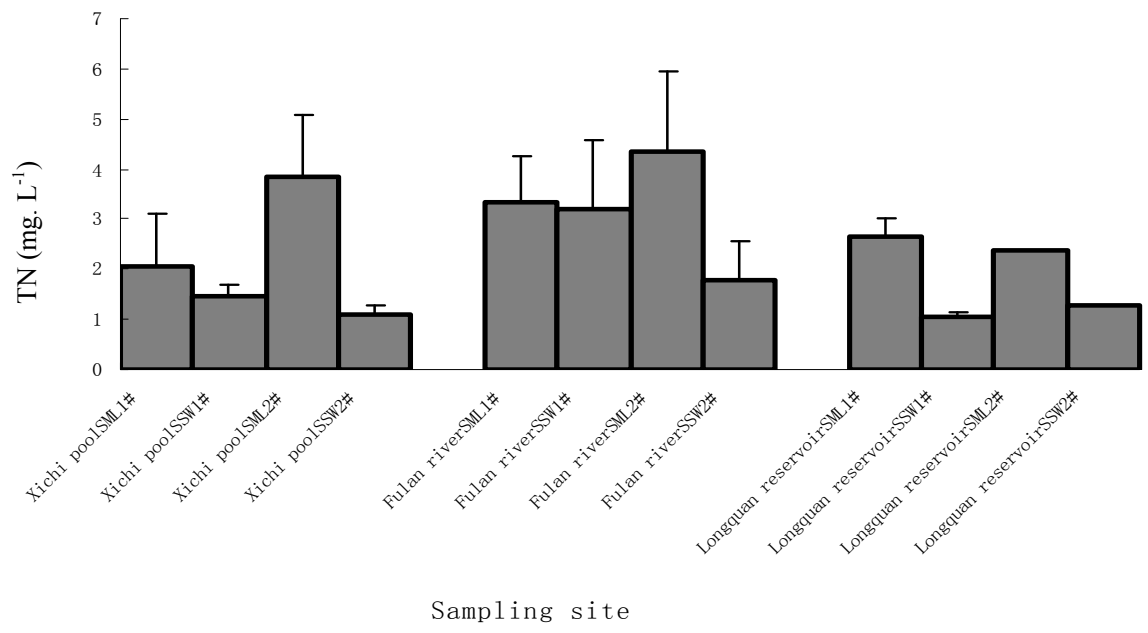

Figure 3. TN contents of SML and SSW at different sampling sites in Xichi pool, Funan River and Longquan reservoir. 


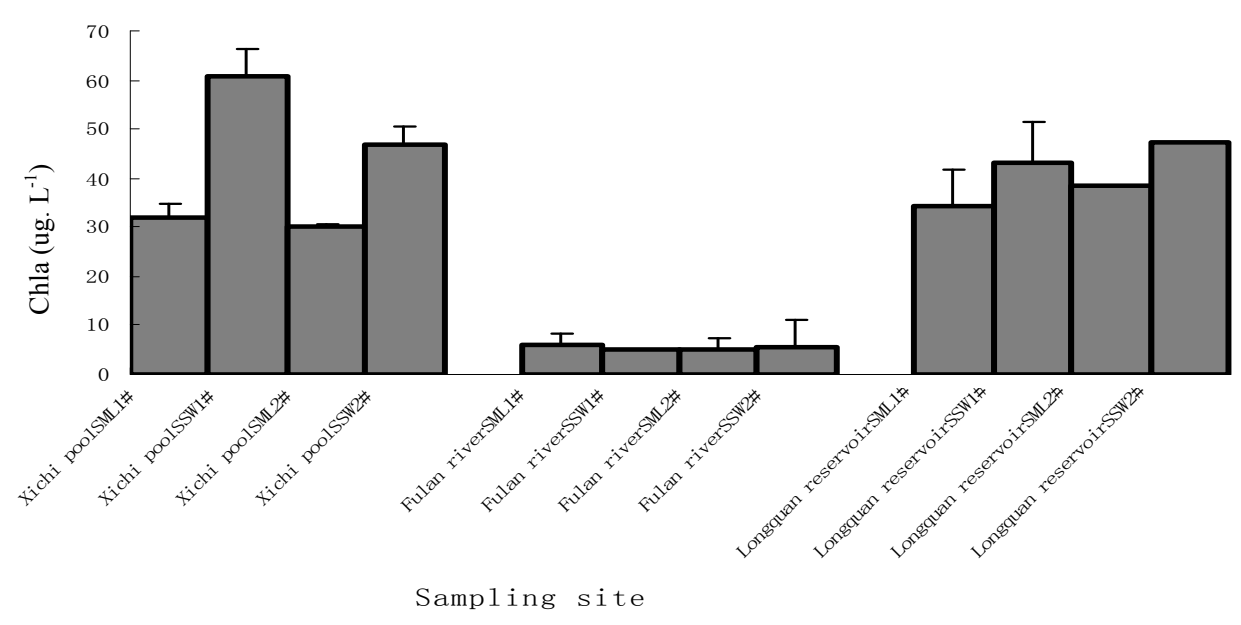

Figure 4. Chl. $a$ contents of SML and SSW at different sampling sites in Xichi pool, Funan River and Longquan reservoir.

\subsection{Enrichment of SML to N, P and Chl. $a$}

From Table 1, it was obvious that N, P were enriched to some extent at SML in Xichi pool, Funan River and Longquan reservoir, with enrichment rates all reaching $100 \%$. The enrichment of SML to TN, TP was remarkable at $2 \#$ sampling point in Xichi pool, the $\mathrm{EF}_{\mathrm{N}}, \mathrm{EF}_{\mathrm{P}}$ was 2.28, 3.51, respectively. However, the enrichment of SML to Chl. $a$ in Funan River was low, the $\mathrm{EF}_{\mathrm{Chl} .} a$ was only $16.67 \%$.

\subsection{Assessment of Water Body Eutrophication}

The eutrophic indexes (E value) of SML at three types of water samples were higher than those of SSW. The two layers in Funan River were middle eutrophication, and the SML in Xichi pool showed the same, and $50 \%$ of SSW was light eutrophication. $75 \%$ of SML and SSW in Longquan reservoir presented light eutrophic situation, which showed the water quality in Longquan reservoir was better than Xichi pool and Funan River (Table 2). By analyzing the correlation between $\mathrm{E}$ value and COD, TN, TP, Chl. $a$ (Table 3), the results showed that there was a significant positive correlation between $\mathrm{E}$ and COD, TN, TP, and while there had a negative correlation between $\mathrm{E}$ and Chl. $a$, which indicated that water body eutrophication of SML might be limited by nitrogen and phosphorus.

\section{Discussion}

Many studies indicate that the microlayer is generally enriched with various organisms and chemical substances and considered to exhibit distinct physical, chemical and biological properties due to the accumulation of surface-active material within this thin layer [12-14]. Peng et al. [15] observed that BOD and COD average enrichment factor of sea and air interface SML was 3.00 and 3.28, respectively in Daya Bay. Our investigation shows that SML of different kinds of fresh water bodies can enrich to $\mathrm{N}$ and P. Pollution of SML is becoming more serious due to SML enriching to many pollutants. The study also shows that COD, TN, TP of SML in Xichi pool and Funan River is obviously higher than the ones of SSW, and the water quality exceeds III and IV level standard.

Eutrophication is an excess of organic substances and $\mathrm{N}, \mathrm{P}$ nutrient, which will bring algae bloom. It is certain that algae quantity is too much with little types, and the algae variety index decreases, dissolved oxygen of lake upper layer is too high and the one of lower layer is too low, and the water quality is getting steadily worse. As we can know from Figure 1 to Figure 3, most of TN, TP, COD of SML and SSW in Xichi pool and Funan River exceed the level in comparison with national III level of water standard, which indicates that pollution for matters containing nitrogen, phosphorus is severe and the water quality is getting worse. According to the eutrophic evaluation criteria, SML and SSW at sampling points are in a eutrophic level, especially in Funan River. It is known from Table 3, there is a significant difference between $\mathrm{E}$ of SML and COD, TP and TN in three types of water bodies $(\mathrm{p}<0.05)$, which can indicates that eutrophication is mainly restricted by nitrogen and phosphorus in three types of water bodies.

Moreover, this investigation indicates that Chl. $a$ mass concentration at SML and SSW in Funan River are prominently lower than those in Xichi pool and Longquan reservoir. The reason might be that large runoff volume of Funan River, muddy river water, fast flow velocity, flow erosion and dilution in the high flow period (May to June) which decreases the cell number of plankton, and further causes Chl. $a$, a comprehensive index of biomass of phytoplankton in water, to decrease. 
Table 1. Enrichment factor of SML to P, N, Chl. $a$ in three kinds of typical water bodies.

\begin{tabular}{ccccccc}
\hline Index & \multicolumn{2}{c}{ Xichi pool } & \multicolumn{2}{c}{ Funan River } & \multicolumn{2}{c}{ Longquan reservoir } \\
\cline { 2 - 7 } & $1 \#$ & $2 \#$ & $1 \#$ & $2 \#$ & $1 \#$ & $2 \#$ \\
TP & 1.16 & 2.28 & 1.01 & 1.02 & 1.25 & 1.96 \\
TN & 1.42 & 3.51 & 1.04 & 2.41 & 2.49 & 1.88 \\
Chla & 0.52 & 0.64 & 1.15 & 0.88 & 0.79 & 0.81 \\
\hline
\end{tabular}

Table 2. Eutrophic status of SML and SSW in three kinds of typical water bodiese.

\begin{tabular}{cllcccc}
\hline Layer Pollution & \multicolumn{2}{c}{ Xichi pool } & \multicolumn{2}{c}{ Funan River } & \multicolumn{2}{c}{ Longquan reservoir } \\
\cline { 2 - 7 } & $1 \#$ & $2 \#$ & $1 \#$ & $2 \#$ & $1 \#$ & $2 \#$ \\
SML E-value & 63.71 & 66.78 & 63.52 & 65.54 & 60.31 & 59.48 \\
Eutrophic Level & $\mathrm{M}$ & $\mathrm{M}$ & $\mathrm{M}$ & $\mathrm{M}$ & $\mathrm{M}$ & $\mathrm{L}$ \\
SSW E-Value & 62.81 & 58.37 & 61.95 & 60.22 & 56.06 & 53.96 \\
Eutrophic Level & $\mathrm{M}$ & $\mathrm{L}$ & $\mathrm{M}$ & $\mathrm{M}$ & $\mathrm{L}$ & $\mathrm{L}$ \\
\hline
\end{tabular}

Remarks: M to be moderation; $\mathrm{L}$ to be light.

Table 3. The relationship of E value and COD, TN, TP and Chl. $a$ of SML.

\begin{tabular}{clc}
\hline Index & Regression Equation & $\mathrm{p}$ \\
\hline COD & $\mathrm{y}=2.002 \mathrm{x}+48.906, \mathrm{R}^{2}=0.7508, \mathrm{n}=12$ & $<0.05$ \\
TN & $\mathrm{y}=1.3572 \mathrm{x}^{2}-6.3862 \mathrm{x}+69.077, \mathrm{R}^{2}=0.5631, \mathrm{n}=12$ & $<0.05$ \\
TP & $\mathrm{y}=27.12 \mathrm{x}+57.537, \mathrm{R}^{2}=0.8078, \mathrm{n}=12$ & $<0.05$ \\
Chl. $a$ & $\mathrm{y}=-0.0239 \mathrm{x}^{2}+0.8705 \mathrm{x}+60.604, \mathrm{R}^{2}=0.73, \mathrm{n}=12$ & $<0.05$ \\
\hline
\end{tabular}

However, much higher TN, TP, COD contents in Funan River still make E value increase and result in these waters to be eutrophic.

\section{Acknowledgements}

The project is supported by Youth Research Fund of Sichuan University (2009SCU11055), Key Laboratory of Aquatic Eutrophication and Control of Harmful Algal Blooms of Guangdong Higher Education Institutes. Special thanks are due to Dr. Liu Qing (Jinan University, in China) and Dr. Liu (Aalborg University, in Denmark) for the experimental study and very valuable comments and on the manuscript.

\section{References}

[1] G. P. Yang, W. W. Jing and Z. Q. Kang, "Spatial Variations of Dimethylsulfide and Dimethylsulf on Propionate in the Surface Microlayer and in the Subsurface Waters of the South China Sea during Springtime," Marine Environmental Research, Vol. 165, 2008, pp. 85-97.

[2] U. Munster, E. Heikkinen and J. Knulst, "Nutrient Composition, Microbial Biomass and Activity at the AirWater Interface of Small Boreal Forest," Hydrobiologia, Vol. 363, No. 1-3, 1998, pp. 261-270.

[3] C. Guitart, N. Garciaflor and J. M. Bayona, "Occurrence and Fate of Polycyclic Aromatic Hydrocarbons in the Coastal Surface Microlayer," Marine Pollution Bulletin, Vol. 54, No. 2, 2007, pp. 186-194.

[4] J. R. Kucklick and T. F. Bidleman, "Organic Contami- nants in Winyah Bay, South Carolina 1. Pesticides and Polycyclic Aromatic-Hydrocarbons in Subsurface and Microlayer Waters," Marine Environmental Research, Vol. 37, 1994, pp. 63-78.

[5] A. M. A. Abd-Allah, "Organochlorine Contaminants in Microlayer and Subsurface Water of Alexandria Coast, Egypt," Journal of AOAC International, Vol. 82, No. 2, 1999, pp. 391-398.

[6] J. Chi, G. L. Huang, X. Lu, et al., "DEHP Enrichment in the Surface Microlayer of a Small Eutrophic Lake," Water Research, Vol. 37, No. 19, 2003, pp. 4657-4662.

[7] M. X. Pan, Z. B. Zhang and A. D. Wang, "Biological and Chemical Studies of Sea-Surface Microlayer at Daya Bay II . (B) Diurnal Variations of Biological and Chemical Characteristics," Tropic Oceanology, Vol. 19, No. 2, 2000, pp. 57-63.

[8] J. T. Harvey and L. A. Burzell, "A Simple Microlayer Method for Small Samples," Limnology Oceanology, Vol. 17, No. 1, 1972, pp. 156-157.

[9] J. Crank, "The Mathematics of Diffusion," 2nd Edition, Oxford University Press, London, 1975.

[10] National Environmental Protection Bureau, "Analytical Methods for the Examination of Water and Wastewater," 2nd Edition, Environmental Science Press, Beijing, 1997.

[11] X. C. Jin, H. L. Li and Q. Y. Tu, "Eutrophication of Lakes in China," Chinese Environmental Science Publication, Beijing, 1990.

[12] B. P. Deng and Y. F. Yang, "Comparative Studies on Water Quality and Community Structure of Zooplankton between the Sea Surface Microlayer and the Subsurface Microlayer in Mar-Culture Areas in Dapeng Cove," Journal of Jinan University (Natural Science), Vol. 30, 
No. 3, 2009, pp. 101-105 (in Chinese with English Abstract).

[13] J. Yu, Y. F. Yang and C. C. Yang, "Study on the Eutrophic Status and the Genetic Toxicity of Water Body in Certain Sections of the Pearl River and Several Artificial Lake," Journal of Chongqing University (Natural Science Edition), Vol. 30, No. 9, 2007, pp. 139-143 (in Chinese with English Abstract).
[14] O. Wurl and J. P Obbard, "A Review of Pollutants in the Sea Surface Microlayer (SML): A Unique Habitat for Marine Organisms," Marine Pollution Bulletin, Vol. 48, No. 11-12, 2004, pp. 1016-1030.

[15] Y. H. Peng, Z. D. Wang, M. X. Pan, et al., "Studies on BOD and COD of Sea Surface Microlayer (MSL) and Subsurface Layer (SSL) water in Day Bay," Transactions of Oceanology and Limnology, Vol. 4, 2000, pp. 13-19. 